\title{
Human induced pluripotent stem cell-derived neural stem cells survive, migrate, differentiate, and improve neurologic function in a rat model of middle cerebral artery occlusion
}

Ting Yuan ${ }^{1+}$, Wei Liao ${ }^{3+}$, Nian-Hua Feng ${ }^{4}$, Yuan-Lei Lou ${ }^{4}$, Xin Niu' ${ }^{1}$ Ai-Jun Zhang ${ }^{2}$, Yang Wang ${ }^{1,4^{*}}$ and Zhi-Feng Deng ${ }^{2,3^{*}}$

\begin{abstract}
Introduction: Stroke is a major cause of permanent neurologic damage, with few effective treatments available to restore lost function. Induced pluripotent stem cells (iPSCs) have the potential to generate all cell types in vitro and can be generated from a stroke patient. Therefore, iPSCs are attractive donor sources of genetically identical "patient-specific" cells to hold promise in therapy for stroke. In the present study, we established a four-stage culture system by using serum-free medium and retinoic acid (RA) to differentiate iPSCs into neural stem cells (NSCs) effectively and stably. Our hypothesis was that iPSC-derived NSCs would survive, migrate, and differentiate in vivo, and improve neurologic function after transplantation into the brains of rats with ischemic stroke.

Methods: Human iPSCs (iPS-S-01) and human ESCs (HuES17) were used to differentiate into NSCs by using our four-stage culture system. iPSCs and differentiated NSCs were characterized by immunocytochemistry staining and reverse transcription-polymerase chain reaction (RT-PCR) analysis. After establishment of focal cerebral ischemia with occlusion of the middle cerebral artery (MCA) and cell transplantation, animals were killed at 1 week and 2 weeks to analyze survival, migration, and differentiation of implanted cells in brain tissue. Animal behavior was evaluated via rope grabbing, beam walking, and Morris water maze tests.

Results: IPSCs were efficiently induced into NSCs by using a newly established four-stage induction system in vitro. iPSCs expressed pluripotency-associated genes Oct4, Sox2, and Nanog before NSC differentiation. The iPSC-derived NSCs spontaneously differentiated into neurons and astrocytes, which highly express $\beta$-tubulin and glial fibrillary acidic protein (GFAP), respectively. On transplantation into the striatum, CM-Dil labeled iPSC-derived NSCs were found to migrate into the ischemia area at 1 week and 2 weeks, and animal-function recovery was significantly improved in comparison with control groups at 3 weeks.

Conclusions: The four-stage induction system is stable and effective to culture, differentiate, and induce iPSCs to NSCs by using serum-free medium combined with retinoic acid (RA). Implanted iPSC-derived NSCs were able to survive, migrate into the ischemic brain area to differentiate into mature neural cells, and seem to have potential to restore lost neurologic function from damage due to stroke in a rat model.
\end{abstract}

Keywords: Induced pluripotent stem cell, Stoke, Neural stem cell, Middle cerebral artery occlusion

\footnotetext{
* Correspondence: wangy63cn@126.com; dengzf63@126.com

${ }^{\dagger}$ Equal contributors

'Department of Orthopaedic Surgery, Shanghai Jiaotong University Affiliated

Sixth People's Hospital, Shanghai 200233, China

2Department of Neurosurgery, Shanghai Jiaotong University Affiliated Sixth

People's Hospital, Shanghai 200233, China

Full list of author information is available at the end of the article
} 


\section{Introduction}

Stroke is one of the leading causes of death and disability in humans. Currently, no effective treatments can restore lost neurologic function after stroke in the clinic $[1,2]$. An increasing number of studies have provided evidence that cell transplantation can lead to the repair of damaged brain tissue and functional recovery in preclinical stroke models [3-8], including transplantation of bone marrow stromal cells (BMSCs) $[9,10]$, neural stem cells (NSCs) [11,12], and embryonic stem cells (ESCs) $[13,14]$. These stem cells can differentiate into neural lineages to replace lost neurons and partially reconstruct damaged neuronal circuitry. Nevertheless, disadvantages such as immune rejection and less differentiation potential of adult stem cells, as well as ethical considerations of ESCs, now limit their utility in clinical trials.

The establishment of induced pluripotent stem cells (iPSCs) offers new prospects for regenerative medicine in stroke. iPSCs behave in a manner similar to that of ESCs with high reproduction ability and pluripotency to differentiate into various types of cells [15]. Furthermore, iPSCs can be generated from cells of any part of an adult patient, avoiding both ethical problems and immune rejection, and have a potential to provide genetically identical "patient-specific" cells for stroke patients.

iPSCs have been shown to differentiate successfully into neural precursor cells, neurons, hematopoietic cells, cardiomyocytes, smooth muscle cells, vascular endothelial cells, and so on, in vitro [16-19]. Some in vivo studies have confirmed that iPSCs transplanted directly into the cerebral tissue of ischemic stroke rats could differentiate into neurons and promote functional recovery [20,21], but only a very small number of implanted cells exhibited the specific markers of neurons. Furthermore, a portion of grafted iPSCs formed tumors in implanted sites [21]. These results indicate that the differentiation ability of iPSCs into neurons is limited and associated with unacceptable high rates of tumor formation. Therefore, if iPSCs are induced into NSCs before transplantation in vitro, it is possible to improve the effectiveness of cell therapy, while reducing the risk of tumor formation.

Retinoic acid (RA) has been shown to have the potential to improve the differentiation of ESCs into NSCs $[22,23]$, but the efficiency is low. In recent years, the alternative serum-free induction protocols have been used widely to differentiate ESCs to NSCs for the advantage of definite components of culture medium, but this induction process needs a long time [24,25]. We used a modified protocol (a four-stage culture system) combining RA induction and serum-free medium culture. The human iPSCs and ESCs were efficiently induced into neural precursor cells and then differentiated into mature neural cells in this newly established four-stage culture system. After we induced them from iPSCs to NSCs, we implanted iPSC-derived NSCs stereotactically into the striatum of rats with ischemic stroke. To evaluate their therapeutic potential, we observed the differentiation, migration, and distribution of grafted cells after transplantation, and analyzed the neurologic and functional status. To our knowledge, we are the first to study the effects of combining RA and serum-free medium to induce iPSCs into NSCs and observe the direct migration of human iPSC-derived NSCs from implanted sites to ischemic brain areas to restore lost neurologic function in a rat model.

\section{Materials and methods \\ Human iPSCs culture}

Human iPSCs (iPS-S-01) and human ESCs (HuES17) were provided by the Institute of Biochemistry and Cell Biology of the Chinese Academy of Sciences in agreement with Liao J and Xiao L [26]. The iPS-S-01 cells were induced by six transcription factors (Oct4, Sox 2 , Nanog, Lin28, C-myc, and Klf4) and resembled the phenotype and pluripotency of undifferentiated human ESCs [26]. Both iPSCs and ESCs were maintained on mouse embryonic fibroblast (MEF) feeder layer, which was inactivated by mitomycin. The medium was changed every day. In general, every 5 to 7 days, when colonies approached approximately $70 \%$ confluence, or greater than 700 microns, the cultured cells were then passaged by $1 \mathrm{mg} / \mathrm{ml}$ collagenase type IV and mechanical dissociation, and split at a 1:4 to 1:6 ratio. The medium for iPSCs and ESCs culture consisted of Knockout DMEM supplemented with $20 \%$ Knockout serum replacement, $1 \%$ nonessential amino acid, $1 \mathrm{mM}$ L-glutamine, $0.1 \mathrm{mM}$ $\beta$-mercaptoethanol, and $4 \mathrm{ng} / \mathrm{ml}$ bFGF (Gibco, Grand Island, NY, USA).

\section{Neural differentiation}

Our protocol for neural differentiation is outlined later (Figure 1A) and divided into four stages. Colonies of iPSCs and ESCs were detached and pooled together in EB (embryoid body) medium (iPSCs medium without bFGF) in suspension culture in low-attachment Petri dishes for 4 days and grown as EBs (stage 1), which further were used for neural differentiation. The collected EBs were divided into three groups randomly: spontaneous differentiation group (EBs were cultured in EB medium for 11 days), retinoic acid (RA) induction group (EBs were in adherent culture in EB medium supplied with $5 \times 10^{-7} M$ RA for 4 days, and then transferred to EB medium for 7 days), RA and serum-free medium induction group (EBs were cultured in EB medium supplied with $5 \times 10^{-7} M$ RA for 4 days and then transferred to serum-free medium for 7 days) (stage 2). The serum-free medium consisted of DMEM/F12 (1:1), EGF (20 ng/ml), 

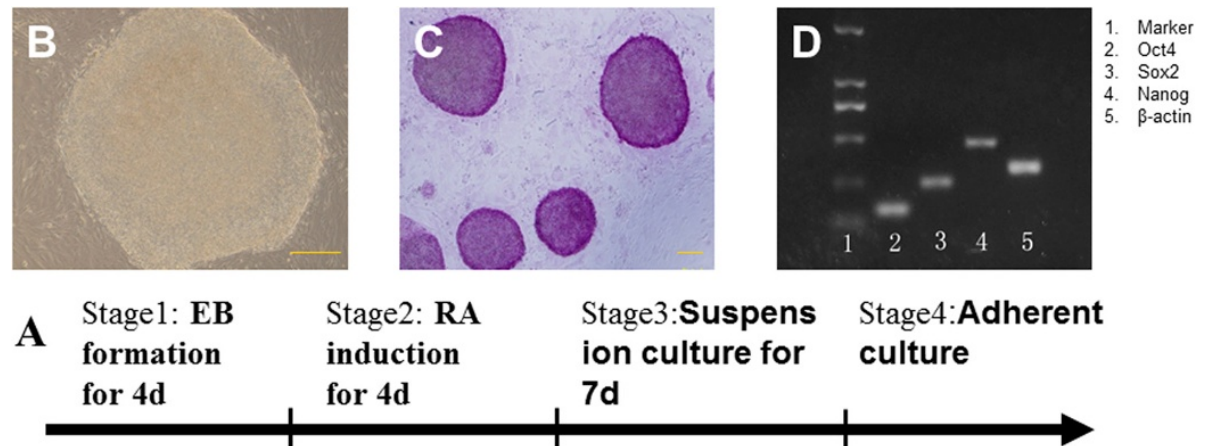

\section{Stage2: RA}

Stage3:Suspens induction ion culture for

Stage4:Adherent for $4 d$ $7 \mathrm{~d}$
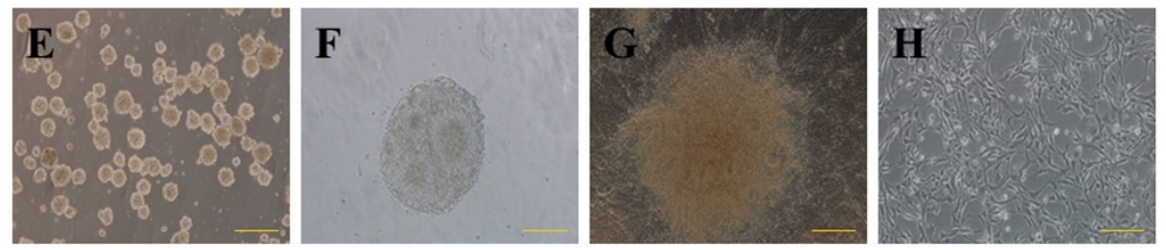

Figure 1 Cell culture and induction of NSCs from iPSCs $(b a r=50 \mu m)$. The stages for neuronal differentiation (A). iPSCs culture and identification (B through $\mathbf{H}$ ). iPSCs maintained on a feeder layer tended to form packed clones with a high nucleus-to-cytoplasm ratio (B), displayed a high level of alkaline phosphatase (C), RT-PCR shows that iPSCs expressed pluripotent genes Oct4, Sox2, Nanog (D). EBs in suspending condition for 4 days and initiated the differentiation program $\mathbf{( E )}$, spheres formed neural-tube like rosette structures $(\mathbf{F})$, neural-tube-like rosette structures in the center of adherent spheres $\mathbf{( G )}$, network-like structure formed after the spheres were cultured in a laminin-coated flask for 1 month $(\mathbf{H})$.

bFGF (10 ng/ml), B27 (2\%), LIF (10 ng/ml), and heparin sodium $(2 \mu \mathrm{g} / \mathrm{ml})$ (all from Gibco). When RA-induced aggregates grew in media without RA, some cells detached from dish bottom and suspended and grew (stage 3). These suspended cells then formed neural spheres, which were then plated on poly-1-ornithine $(10 \mathrm{mg} / \mathrm{ml}) /$ laminin $(5 \mu \mathrm{g} / \mathrm{ml})$-coated dishes in the serum-free medium for adherent culture up to 7 days (stage 4). The cells were split $1: 3$ to $1: 4$ with a cell-detachment enzyme (Accutase) every 5 to 7 days.

\section{Establishment of focal cerebral ischemia and cell transplantation}

All animal procedures were approved by the Institutional Animal Care and Use Committee of Jiangxi Province, China. All experiments on animals were carried out in an ethical manner. Adult male Sprague-Dawley rats (250 to $300 \mathrm{~g}$ ) were used to establish the model of middle cerebral artery occlusion (MCAO), as previously described [27]. Rats were anesthetized, and a 4-0 nylon intraluminal suture was introduced from the minimal incision of the external carotid artery into the internal carotid artery at about a depth of $18 \mathrm{~mm}$ to $20 \mathrm{~mm}$ until it blocked the origin of the MCA. After 2-hour temporary MCA occlusion, reperfusion was performed by withdrawal of the suture. The rats with significant neurologic deficit of the left forelimb, according to the Longa 5-point scale [27], were chosen as candidates for cell transplantation. Sham-operated animals underwent the same surgical procedure without suture insertion.
Two days before cell transplantation, all rats were immunosuppressed with a daily injection of cyclosporin A $(20 \mathrm{mg} / \mathrm{kg})$ and lasting for 1 week [28]. The NSCs were dissociated with Accutase to single cells, then were collected and labeled with CM-DiI before injection into the ischemia striatum (Figure 2A) by using a stereotactic apparatus (Zhenghua Biological Instruments Co., Ltd. Anhui Province, China). Based on a previously published article [29], the iPSC-derived NSCs $\left(10^{6}\right.$ cells in $30 \mu \mathrm{l}$ PBS) solution was injected into the striatum site, which was $0.8 \mathrm{~mm}$ behind the anterior fontanel, $3.4 \mathrm{~mm}$ left to the sagittal suture, and the injection depth was $5.8 \mathrm{~mm}$. The injection was performed immediately once the reperfusion began, the time was controlled within $10 \mathrm{mi}$ nutes for a constant speed, and the needle was left in for an additional 5 minutes before removal. The rats were randomly divided into three groups (each group, $n=5$ ): sham group, iPSCs-derived NSCs transplantation group, PBS transplantation group; and the transplantation group was further divided into two subgroups: transplantation for 7 days, transplantation for 14 days. The neurologic scores were determined before and after the cell transplantation. After 7 and 14 days from cell transplant, the rats were killed after deep anesthesia and were transcardially perfused with $4 \%$ paraformaldehyde. Dissected whole brains were fixed with $4 \%$ paraformaldehyde for 2 hours and were dehydrated by using sucrose density gradient at $20 \%$ to $30 \%$ for each day. The $8-\mu \mathrm{m}$ frozen sections were prepared for immunocytochemistry staining. 


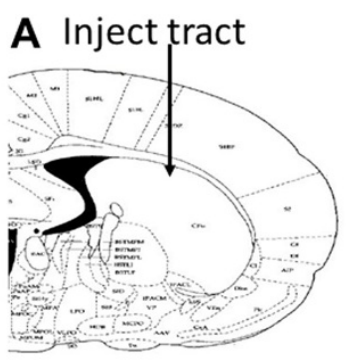

\section{C}

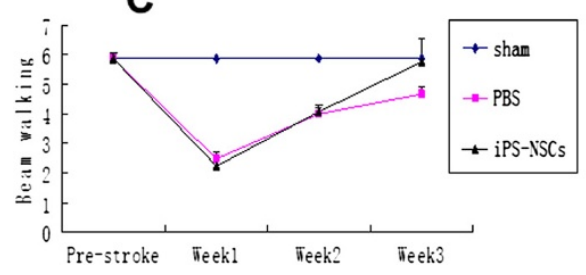

B
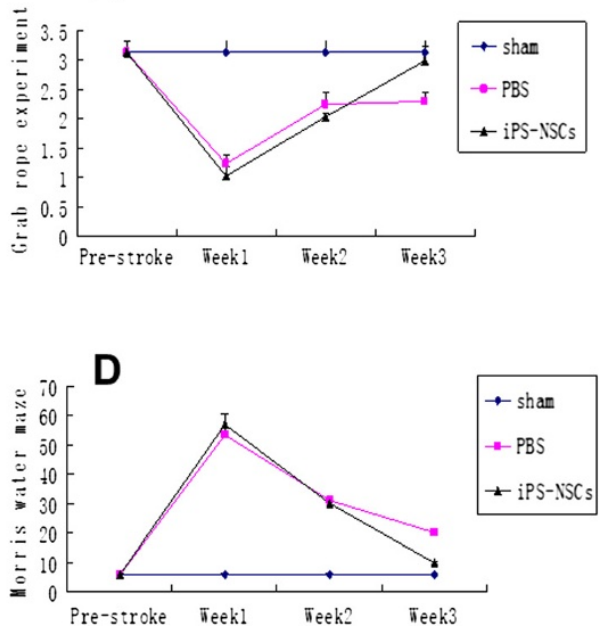

Figure 2 Transplanted cells improved the behavioral and sensorimotor function of the models. The NSCs derived from iPSCS cultured in RA and serum-free medium for 1 month were transplanted into the striatum of the animal brains (A); rope-grabbing experiment (B), beamwalking (C), and Morris water maze (D) score. (Compared with the sham and PBS groups).

\section{Immunocytochemistry staining}

Cells and rat brains were fixed with $4 \%$ paraformaldehyde for 15 minutes. Nonspecific sites were blocked with $1 \% \mathrm{BSA} / \mathrm{PBS}$ (for extracellular epitopes) or 1\% BSA/ PBS/0.5\% triton X-100 (for intracellular epitopes) for 30 minutes at $37^{\circ} \mathrm{C}$. Then the specimens were incubated with primary antibodies at $4^{\circ} \mathrm{C}$ overnight. The redundant primary antibodies were removed by washing with PBS for 5 minutes and repeated 3 times the next day. Second antibodies labeled with FITC were used. Nuclei were stained with 4,6-diamidino-2-phenylindole (DAPI, $0.5 \mu \mathrm{g} /$ $\mathrm{ml}$, Invitrogen, Grand Island, NY, USA). The following antibodies were used: Anti-Nestin (monoclonal, Santa Cruz Biotechnology, Santa Cruz, CA, USA), Anti-Sox2 (monoclonal, Cell Signaling, Danvers, MA, USA), Anti- $\beta$ -Tubulin (monoclonal, Chemicon, Billerica, MA, USA), Anti-glial fibrillary acidic protein (GFAP, monoclonal, Santa Cruz Biotechnology), Anti-Oct3/4 (monoclonal, Cell Signaling, Danvers, MA, USA). Primary and secondary antibodies were diluted in 1\% BSA (Roche, Indianapolis, IN, USA) at 1:100 and 1:200, respectively. Fluorescence was observed under a fluorescence microscope (Olympus, Tokyo, Japan), and photos were taken with a DP70 digital camera system (Olympus). Positive cells in brain tissue were counted blindly in five coronal sections per animal.

Reverse transcription-polymerase chain reaction analysis Total RNA was extracted from cultured cells by using Trizol reagent (Invitrogen). $1 \mu \mathrm{g}$ of total RNA from the cells was used for the synthesis of the first-strand cDNA with a Revert Aid first-strand cDNA synthesis kit (Fermentas, Life Sciences, Burlington, ON, Canada) in a total volume of $20 \mu \mathrm{l}$. For quantitative PCR, SYBR Green supermix was used, and standard curves for each primer set were generated to confirm that only one amplicon was generated at the same efficiency as the reference gene GAPDH. PCR was performed by using the following thermal profile: 10 minutes at $95^{\circ} \mathrm{C}$; denature at $95^{\circ} \mathrm{C}$ for 15 seconds, annealing for 30 seconds at $60^{\circ} \mathrm{C}$, elongation at $72^{\circ} \mathrm{C}$ for 30 seconds, for 40 cycles; extension for 10 minutes at $72^{\circ} \mathrm{C}$, and finally paused at $4^{\circ} \mathrm{C}$. Relative expression was calculated by using the comparative $\mathrm{Ct}$ method $\left(2^{-\Delta \Delta C t}\right) \cdot 2^{-\Delta \Delta C t}>3$ or $<1 / 3$ was deemed statistically significant. The PCR primers special to each transcript were as follows (Table 1). (All primers were designed by using the Primer Designer software).

\section{Neurobehavioral evaluation}

Neurobehavioral evaluation was performed according to the previously published studies [30-32]. The rats were subjected to behavioral testing 1, 2, and 3 weeks after MCAO modeling, by using the rope-grabbing experiment

Table 1 Primers used for reverse transcriptionpolymerase chain reaction (RT-PCR) analysis

\begin{tabular}{|c|c|c|}
\hline Genes & Forward $\left(5^{\prime}-3^{\prime}\right)$ & Reverse $\left(5^{\prime}-3^{\prime}\right)$ \\
\hline GAPDH & GGCATGGACTGTGGTCATGAG & TGCACCACCAACTGCTTAGC \\
\hline Oct4 & $\begin{array}{l}\text { CGA AGAGAAAGCGAACCA } \\
\text { GTATC }\end{array}$ & $\begin{array}{l}\text { AGAACCACACTCGGACCACA } \\
\text { TC }\end{array}$ \\
\hline Sox 2 & CCCC CGG CGGCAATAGCA & TCGGCGCCGGGG AGATACAT \\
\hline Nestin & GCCCTGACCACTCCAGTTAAG & $\begin{array}{l}\text { CCCTCTATGGCTGTTTCTTTC } \\
\text { TCTAC }\end{array}$ \\
\hline GFAP & GAAGCTCCAGGATGAAACCA & ACCTCCTCCTCGTGGATCTT \\
\hline$\beta$-tubulin & CTGGTGGAGAACACGGATGAG & GCGGAAGCAGATGTCGTAGAG \\
\hline
\end{tabular}


for assaying the myodynamics of the model, beam walking and Morris water maze for testing the spatial, working memory of the models.

\section{Statistical analysis}

Outcome measurement for each experiment was reported as mean \pm SEM. All data were analyzed by using SPSS 17.0. Significance of intergroup differences and nerveassessment data were analyzed with repeated measures of analysis of variance (ANOVA), and the unpaired Student $t$ test. A $P$ value of less than 0.05 was considered to be statistically significant.

\section{Results}

IPSCs efficiently induced into NSCs with RA and serumfree medium

iPS-S-01 and HuES17 tended to form packed clones with a high nucleus/cytoplasm ratio (Figure 1B) and displayed a high level of alkaline phosphatase (Figure 1C). To make sure of the undifferentiated state of the cells, pluripotency-associated genes Oct4, Sox2, and Nanog were detected with qRT-PCR before the NSC differentiation. The results showed that those cells expressed high levels of pluripotency-associated genes (Figure 1D).
A four-stage induction protocol was used for iPS-S-01 and HuES17 differentiation into the NSC. iPS-S-01 and HuES17 clones were cultured in suspension condition for 4 days and formed embryonic bodies (EB) (Figure 1E). Then these EBs were transferred to serum-free medium supplied with $5 \times 10^{-7} \mathrm{M}$ RA for another 4 days of induction, which promoted the neutralization program. Neural-tube-like rosette structures appeared on the third day (Figure 1F), with the more culture days, the more rosette structures. These spheres expressed uniformly for Nestin and Sox2 (Figure 3A,B) with immunocytochemistry staining. When plated on poly-L-ornithine and laminin precoated flasks and cultured in serum-free medium, iPSC-derived NSCs could also form neuraltube-like rosette structures (Figure 1G). The network-like structures formed after the spheres were cultured in a laminin-coated flask for 1 month (Figure 1H). Accutase was used for the passage of those cells. Immunocytochemistry staining showed that those cells could express Nestin and Sox 2 as highly as before (Figure 3E,F). Whereas the iPSCs-derived NSCs were cultured in medium supplement with fetal bovine serum, iPSCs-derived NSCs spontaneously differentiated to neurons and astrocytes, which highly express $\beta$-tubulin and GFAP, respectively (Figure 3C,D,G,H). The qRT-PCR results demonstrated
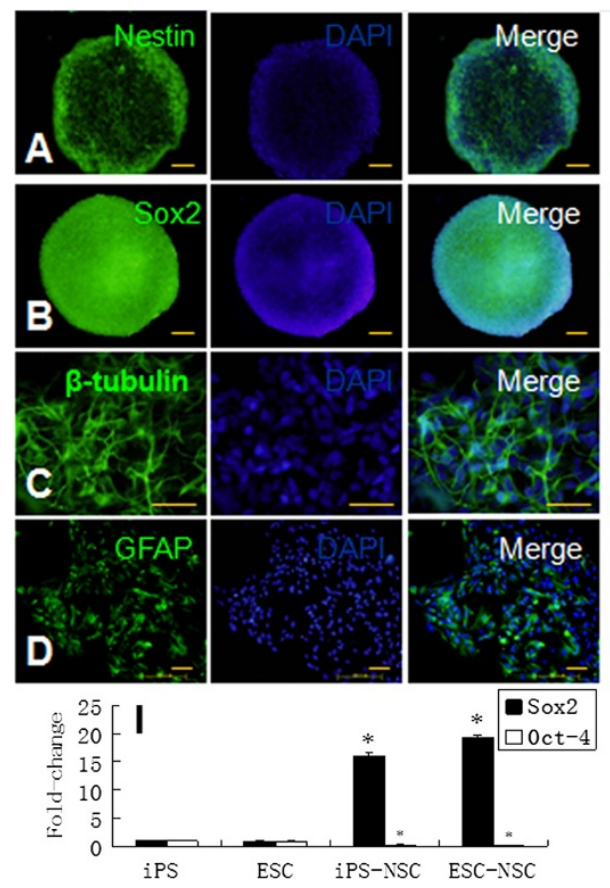
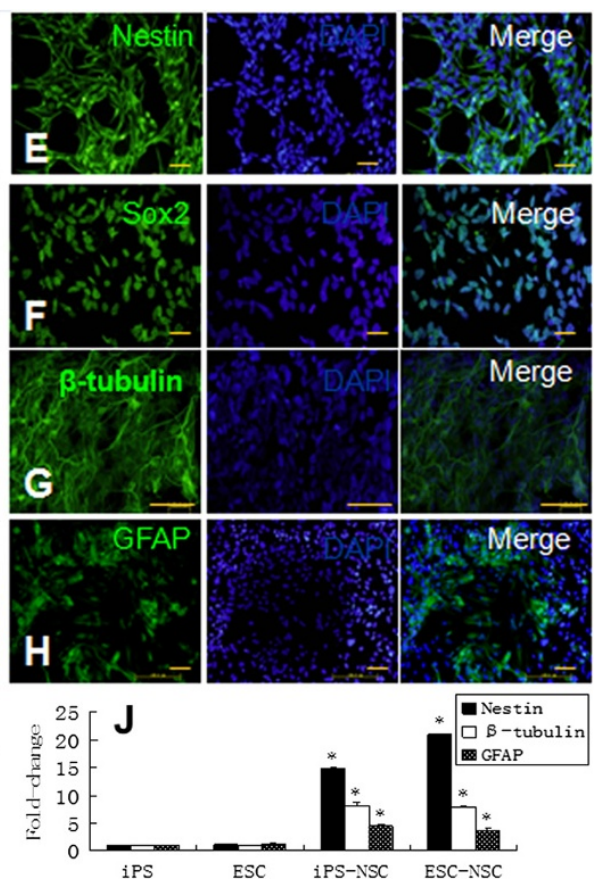

Figure 3 The expression of pluripotent potent and neural markers during the induction process of the iPSCs to NSCs.

Immunocytochemistry staining shows that the spheres expressed the neural precursor markers Nestin (A), Sox2 (B) induced by RA and serum-free medium, and after culture, in serum medium; those spheres expressed the neuron marker $\beta$-tubulin (C) and astrocyte marker GFAP (D). The adherent cells expressed the neural precursor markers Nestin (E), Sox2 (F), and differentiated into neurons and astrocytes in the same conditions $(\mathbf{G}, \mathbf{H})$. The expression of pluripotent genes Sox2 and Oct4 during the induction process in the iPSCS and ESCs (I); the iPSC-derived NSCs expressed high levels of Nestin, $\beta$-tubulin, and GFAP during the induction process and showed a similar tendency to the ESC-derived NSCs $\left(\mathbf{J}^{*}{ }^{*}\right.$ Compared with ESCs; $\left.P<0.05\right)$. 
that the pluripotent stem cell gene Sox2 expression was increased, and Oct4 expression was decreased during the induction process (Figure 3I). Both the iPSC-derived NSCs and the ESC-derived NSCs expressed high levels of Nestin, $\beta$-tubulin, and GFAP (Figure 3J).

To test whether iPSCs cultured in serum-free medium combined with RA could be efficiently differentiated into NSCs, we chose three groups to compare: RA induction group, RA and serum-free medium induction group, and spontaneous differentiation group. The cells were collected on days 7 . The qRT-PCR results indicated that the expression levels of Nestin in RA induction group as well as RA and serum-free medium induction group were significantly higher than the spontaneous differentiation group. The fold changes were $3.71 \pm 0.63$ and $7.14 \pm 1.96$, respectively (Figure $4 \mathrm{~A}$ ). Additionally, the immunostaining results showed that Nestin-positive cell rates were $23.77 \% \pm 2.96 \%, 53.25 \% \pm 4.52 \%$, and $87.54 \% \pm$ $3.67 \%$ (Figure 4B) in the spontaneous-differentiation group, RA-induction group, and RA plus serum-free medium-induction group, respectively. Significant differences were found between groups. It means that the iPSCs can be induced into NSCs highly efficiently with RA and serum-free medium.

Transplanted cells survived and migrated into the strokedamaged host tissue

The brain tissues from weeks 1 and 2 processed for immunocytochemistry staining showed that: amounts of CM-DiI-labeled NSCs derived from iPSCs were found besides the striatum after the cells were transplanted. One week later, the CM-DiI-labeled cells $(68.2 \pm 2.3$ count/field) were found in the models' brains, particularly around the striatum, but less (11.6 \pm 1.8 count/field) in the other areas, which demonstrated that the transplanted cells could survive in the models. Two weeks after transplantation, the majority of cells (37.2 \pm 3.5 count/field) migrated into the ischemia area. The immunocytochemistry staining showed that the grafted cells expressed the Nestin $(68.5 \% \pm 2.8 \%$, Figure $5 \mathrm{~A})$, and a few cells expressed the $\beta$-tubulin $(25.7 \% \pm 12.3 \%$; Figure $5 \mathrm{~B})$ for the 1-week transplantation group. The 2-week transplantation group $(51.4 \% \pm 7.5 \%$ Figure $5 \mathrm{C})$ expressed Nestin, and more grafted differentiated into the neuron $(44.3 \% \pm 2.5 \%$ expressed $\beta$-tubulin Figure 5D) and astrocytes $(11.2 \% \pm 1.4 \%$ expressed GFAP; Figure $5 \mathrm{E})$. These results suggested that the NSCs derived from iPSCs could survive in the models of MCAO and differentiate into the neurons and astrocytes. We did not observe the tumorigenesis during the transplantation process.

\section{Transplanted cells improved the behavioral and sensorimotor function of the rats}

Animal behavior was evaluated with the rope-grabbing, beam-walking, and Morris water-maze tests 0 days, 1,2 , and 3 weeks after MCAO models were prepared. No obvious differences among the groups were found before the MCAO or transplantation. It was found that no obvious sensorimotor and functional differences among the three groups at 0 days and the first and second weeks $(P>0.05)$; but at the third week, the transplantation group showed greater function recovery than did those of the other groups (PBS and sham groups, $P<0.05$ ) (Figure $2 \mathrm{~B}$ through $\mathrm{D}$ ). These results demonstrate that the NSCs derived from iPSCs improved the behavioral and sensorimotor functions in a rat model of MCAO through transplanting cells in the striatum.

\section{Discussion}

In recent years, with the development of regenerative medicine, stem cell transplantation for the treatment of central nervous system disease is considered to be a way of great potential. NSCs derived from iPSCs seem to be the ideal seed cells for transplantation therapy for neurologic diseases. Because iPSCs share similar characteristics and potential with ESCs, we may study iPSCs by applying the same protocols that had been previously developed in ES cells.

Various culture protocols for the generation of NSCs from iPSCs have been reported in many studies, and the
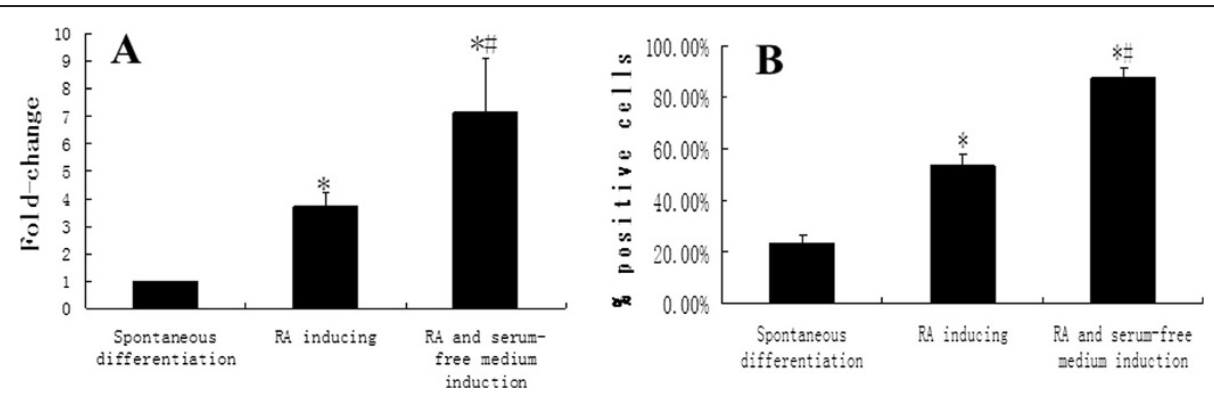

Figure 4 The expression of Nestin during the induction process among the three groups. The quantity of mRNA of Nestin in RA plus serumfree medium group was the highest among the three groups (A). During the induction process, Nestin-positive cell rate was the highest in RA plus serum-free-medium group (B) ( ${ }^{*}$ compared with the spontaneous-differentiation group, $P<0.05$; \#compared with the RA-induction group, $P<0.05$ ). 

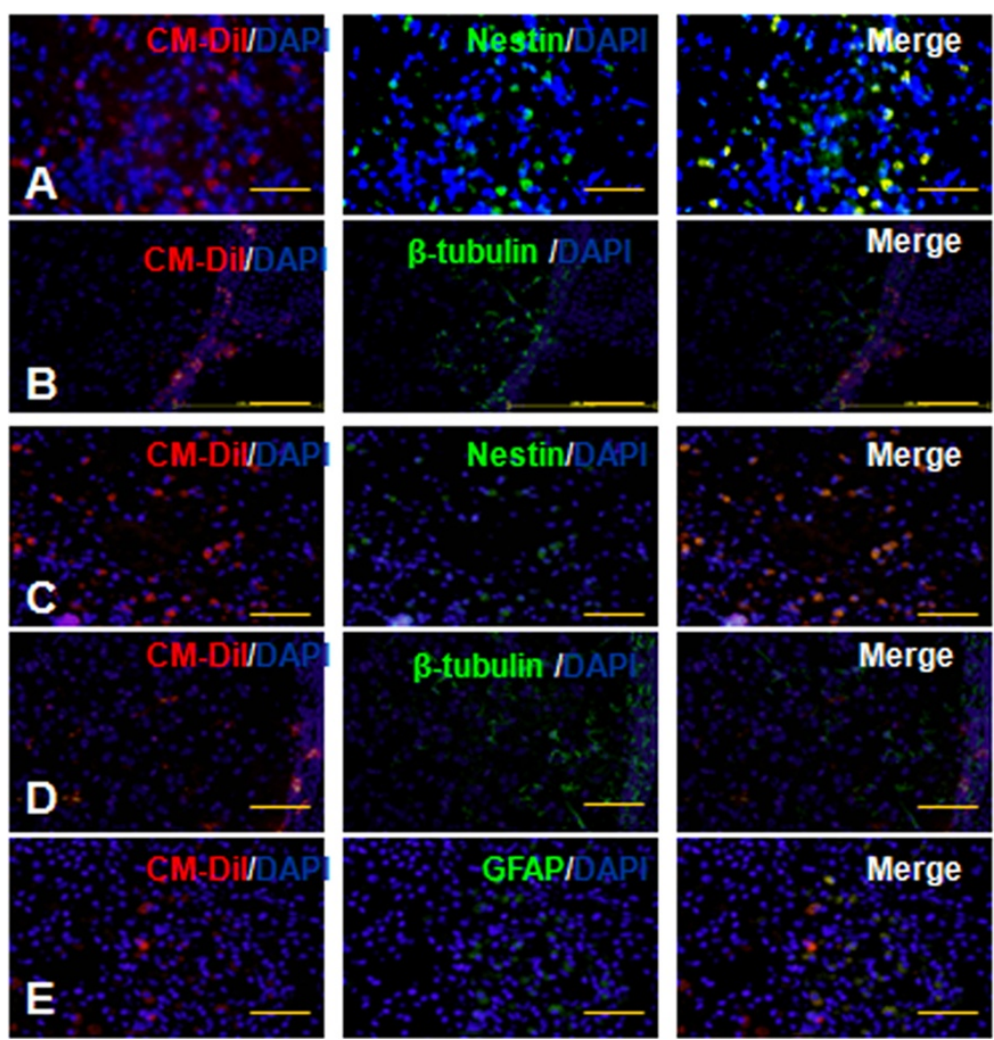

Figure 5 Transplanted cells survived and migrated into the stroke-damaged host tissue $(b a r=100 \mu m)$. The NSCs derived from iPSCs differentiated into neural cells, which were immunopositive for Nestin (A, C) and $\beta$-tubulin (B, D) (A, B: group of transplantation for 7 days; C, D: group of transplantation for 14 days). Two weeks after transplantation, some of the transplanted cells were immunopositive with GFAP (E)

main methods are the following: RA-mediated induction [33], stromal cell coculture, conditioned medium induction, and serum-free-medium induction [25]. RA has been demonstrated to induce significant neural differentiation of ESCs [33-35]. In 1995, Bain [34] used RA to induce mouse ESCs into nerve cells successfully, and these cells had the electrophysiological properties and functions of nerve cells. Later, Zhou and Bahrvand $[36,37]$ reported that the use of RA could promote human ESCs differentiation into neural stem cells, but efficiency was low, and the survival capacity of RA-induced neuronal cells was limited [38]. Stromal cell coculture and conditioned-medium induction are also able to induce ESCs to differentiate into neural cells, but the two methods have a common shortcoming, in that the medium composition is complex, and this complicates the study of its mechanism.

In recent years, induction protocols using cytokines and serum-free medium have been established. Koch [24] successfully used serum-free medium to induce human ESCs into NSCs. The serum-free medium contains $\mathrm{N} 2$, insulin, FGF, and B27, and the data showed that FGF was able to stimulate proliferation and differentiation of a variety of cell types originated from multigerminal layers. A study [39] showed that neuroepithelial precursor cells differentiated from ESCs proliferate in the presence of basic fibroblast growth factor (bFGF), and differentiate into both neurons and glia after withdrawal of bFGF. Daadi [25] successfully induced ESCs into NSCs by using serum-free medium containing bFGF, leukemia inhibitory growth factor (LIF), and EGF. These factors are known to stimulate the proliferation of NSCs, and LIF has the potential to maintain the pluripotency of NSCs and to prevent NSCs from differentiating into neurons. Definite components of serum-free medium are beneficial to study the relation between cell growth and medium components.

In the present study, we established a modified fourstage culture system to induce iPSCs to NSCs by taking the advantages of previously developed protocols, by using RA combined with serum-free medium containing bFGF, EGF, LIF, B27, and heparin sodium to induce iPSCs to NSCs in adherent culture. The results showed that this system was stable and effective to induce neural differentiation of iPSCs. Induced cells expressed high levels of NSC markers, Nestin and Sox2, and have been amplified and passaged in vitro for more than 35 cell generations. 
In addition, NSCs can be expanded and differentiated in both suspension and adherent cultures. However, it is difficult to control the quality and quantity of cells in the process of suspension culture, because ESC-derived neurosphere cells will lose the potential of self-renewal and differentiation gradually during the long suspension culture, and the types of neurosphere cells are very diverse [40-42]. The adherent culture may avoid these shortcomings.

After implantation into the brain in a rat model of stroke, iPSC-derived NSCs were able to survive and express NSC makers. One week after implantation, implanted cells expressed mainly $\beta$-tubulin in addition to Nestin; after 2 weeks, besides continuing to express Nestin and $\beta$-tubulin, a few implanted cells expressed GFAP (maker of astrocytes). These results show that grafted NSCs have the potential to differentiate into neurons and glia, and create the possibility of repairing brain injury or other neurologic defects through a neural cell-replacement strategy.

Tumorigenesis is a big challenge in stem cellreplacement therapy. Some animal studies demonstrated that direct implantation of ESCs or iPSCs led to tumor formation [21,43]. In this study, two rats survived for more than 3 months, and no abnormal proliferation of cells was observed (data not shown). It implied that the implanted cells were not susceptible to tumorigenesis. Although we did not observe tumor formation in this study, it could be that a short period of observation lasting for only 2 weeks was not long enough for tumor development and formation. Therefore, the long-term safety of iPSC-derived NSCs implantation is still a serious problem.

Grafted stem cells have the potential to migrate in vivo. A number of studies [44,45] observed migration of various implanted stem cells into lesions of the brain, and indicated that possibly stem cells are targeted by inflammatory chemotactic factors and cytokines extracted from ischemic brain tissue. This feature of chemotaxis is the pathophysiologic basis of repairing brain injury by cell-implantation therapy. In this study, implanted NSCs were observed migrating from the striatum toward the ischemic boundary at 2 weeks after implantation.

In our study, we observed a significant increase of neurologic scores 3 weeks after transplantation compared with the control groups, demonstrating a positive effect of repairing ischemic brain with iPSC-derived NSCs. Although 3 weeks is long enough for differentiation of implanted NSCs into neurons, it is not enough for implanted cells to replace dead neurons and function. As a result, some scholars $[46,47]$ believe that early recovery of function with stem cell transplantation is due to neurologic protection of growth factor release, not new neural cells replacement. Therefore, restoration of neurologic function in this study after cell implantation may be more relevant to a neuroprotective effect.

Note that PBS injection also improved the behavior of rats at 2 weeks (Figure $2 \mathrm{~B}$ through $\mathrm{D}$ ). One reason is that collateral circulation has been formed in brain tissue, and the function of impaired cells may be recovered in 2 weeks, which contributes to the improved behavior of rats. Moreover, the improvement of behavior in this rat model may be partly owing to functional compensation after brain injury.

\section{Conclusions}

This study established a stable and effective culture system for cell expansion, differentiation, and induction of iPSCs to NSCs in vitro by using serum-free medium combined with RA. After stereotactic implantation of iPSC-derived NSCs into the brain in a rat-stroke model, implanted cells were able to survive, migrate into ischemic brain areas, and differentiate into mature neural cells. Furthermore, this cell-implantation therapy seemed to restore lost neurologic function to a certain extent in a rat stroke model.

\section{Abbreviations}

bFGF: Basic fibroblast growth factor; BMSC: Bone marrow stromal cell; BSA: Bovine serum albumin; DAPI: 4, 6-Diamidino-2-phenylindole; DMEM: Dulbecco modified Eagle medium; EB: Embryoid body; EGF: Epidermal growth factor; ESC: Embryonic stem cell; FITC: Fluorescein isothiocyanate; GFAP: Glial fibrillary acidic protein; iPSC: Induced pluripotent stem cell; LIF: Leukemia inhibitory factor; MCAO: Middle cerebral artery occlusion; MEF: Mouse embryonic fibroblast; NSC: Neural stem cell; PBS: Phosphate-buffered saline; RA: Retinoic acid; RT-PCR: Reverse transcription-polymerase chain reaction.

\section{Competing interests}

The authors declare that they have no competing interests.

\section{Authors' contributions}

ZFD and YW conceived the idea and designed the experiments, TY and WL performed animal experiments, data analysis, and manuscript preparation. $\mathrm{NHF}, \mathrm{YLL}$, and $\mathrm{XN}$ are responsible for cell-culture experiments and the collection and assembly of data. AJZ contributed to animal experiments and neurologic-function analysis. All authors read and approved the final manuscript.

\section{Acknowledgements}

This work was supported by the National S\&T Major Special Project on Major New Drug Innovation (2011ZX09102-010-01), National Nature Science Foundation Grants (81160154,81271270), Nature Science Foundation of Jiangxi Province (2010GZY0256), and the innovation team construction plan of Jiangxi Province (20113BCB24018).

\section{Author details}

${ }^{1}$ Department of Orthopaedic Surgery, Shanghai Jiaotong University Affiliated Sixth People's Hospital, Shanghai 200233, China. ${ }^{2}$ Department of Neurosurgery, Shanghai Jiaotong University Affiliated Sixth People's Hospital, Shanghai 200233, China. ${ }^{3}$ Department of Neurosurgery, The Second Affiliated Hospital of Nanchang University, Nanchang 330006, China. ${ }^{4}$ Institute of Urology, The First Affiliated Hospital of Nanchang University, Nanchang 330006, China.

Received: 1 April 2013 Revised: 1 April 2013

Accepted: 10 June 2013 Published: 14 June 2013 


\section{References}

1. Zhu Y, Wan S, Zhan RY: Inducible pluripotent stem cells for the treatment of ischemic stroke: current status and problems. Rev Neurosci 2012, 23:393-402.

2. Savitz SI: Stem cells and stroke: are we further away than anyone is willing to admit? Int J Stroke 2012, 7:34-35.

3. Peterson DA: Umbilical cord blood cells and brain stroke injury: bringing in fresh blood to address an old problem. J Clin Invest 2004, 114:312-314.

4. Cui X, Chopp M, Zacharek A, Dai J, Zhang C, Yan T, Ning R, Roberts C, Shehadah A, Kuzmin-Nichols N, Sanberg CD, Chen J: Combination treatment of stroke with sub-therapeutic doses of Simvastatin and human umbilical cord blood cells enhances vascular remodeling and improves functional outcome. Neuroscience 2012, 227:223-231.

5. Bhasin A, Padma Srivastava MV, Mohanty S, Bhatia R, Kumaran SS, Bose S: Stem cell therapy: a clinical trial of stroke. Clin Neurol Neurosurg 2012, 115:1003-1008.

6. Ikegame Y, Yamashita K, Hayashi S, Mizuno H, Tawada M, You F, Yamada K Tanaka Y, Egashira Y, Nakashima S, Yoshimura S, Iwama T: Comparison of mesenchymal stem cells from adipose tissue and bone marrow for ischemic stroke therapy. Cytotherapy 2011, 13:675-685.

7. Smith HK, Gavins FN: The potential of stem cell therapy for stroke: is PISCES the sign? FASEB J 2012, 26:2239-2252.

8. Banerjee S, Williamson DA, Habib N, Chataway J: The potential benefit of stem cell therapy after stroke: an update. Vasc Health Risk Manag 2012, 8:569-580.

9. Guo F, Lv S, Lou Y, Tu W, Liao W, Wang Y, Deng Z: Bone marrow stromal cells enhance the angiogenesis in ischaemic cortex after stroke: involvement of notch signalling. Cell Biol Int 2012, 36:997-1004.

10. Liu Z, Li Y, Zhang RL, Cui Y, Chopp M: Bone marrow stromal cells promote skilled motor recovery and enhance contralesional axonal connections after ischemic stroke in adult mice. Stroke 2011, 42:740-744.

11. Chu K, Kim M, Jeong SW, Kim SU, Yoon BW: Human neural stem cells can migrate, differentiate, and integrate after intravenous transplantation in adult rats with transient forebrain ischemia. Neurosci Lett 2003, 343:129-133.

12. Jeong SW, Chu K, Jung KH, Kim SU, Kim M, Roh JK: Human neural stem cell transplantation promotes functional recovery in rats with experimental intracerebral hemorrhage. Stroke 2003, 34:2258-2263.

13. Bjorklund LM, Sanchez-Pernaute R, Chung S, Andersson T, Chen IY, McNaught KS, Brownell AL, Jenkins BG, Wahlestedt C, Kim KS, Isacson O: Embryonic stem cells develop into functional dopaminergic neurons after transplantation in a Parkinson rat model. Proc Natl Acad Sci U S A 2002, 99:2344-2349

14. Hicks $A U$, Lappalainen RS, Narkilahti S, Suuronen R, Corbett D, Sivenius J, Hovatta O, Jolkkonen J: Transplantation of human embryonic stem cellderived neural precursor cells and enriched environment after cortical stroke in rats: cell survival and functional recovery. Eur J Neurosci 2009, 29:562-574

15. Takahashi K, Yamanaka S: Induction of pluripotent stem cells from mouse embryonic and adult fibroblast cultures by defined factors. Cell 2006, 126:663-676.

16. Hanna J, Markoulaki S, Schorderet P, Carey BW, Beard C, Wernig M, Creyghton MP, Steine EJ, Cassady JP, Foreman R, Lengner CJ, Dausman JA, Jaenisch $R$ : Direct reprogramming of terminally differentiated mature $B$ lymphocytes to pluripotency. Cell 2008, 133:250-264.

17. Schenke-Layland K, Rhodes KE, Angelis E, Butylkova Y, Heydarkhan-Hagvall S, Gekas C, Zhang R, Goldhaber Jl, Mikkola HK, Plath K, MacLellan WR: Reprogrammed mouse fibroblasts differentiate into cells of the cardiovascular and hematopoietic lineages. Stem Cells 2008, 26:1537-1546

18. Dimos JT, Rodolfa KT, Niakan KK, Weisenthal LM, Mitsumoto H, Chung W, Croft GF, Saphier G, Leibel R, Goland R, Wichterle H, Henderson CE, Eggan K: Induced pluripotent stem cells generated from patients with ALS can be differentiated into motor neurons. Science 2008, 321:1218-1221.

19. Wernig M, Zhao JP, Pruszak J, Hedlund E, Fu D, Soldner F, Broccoli V, Constantine-Paton M, Isacson O, Jaenisch R: Neurons derived from reprogrammed fibroblasts functionally integrate into the fetal brain and improve symptoms of rats with Parkinson's disease. Proc Natl Acad Sci U S A 2008, 105:5856-5861.

20. Chen SJ, Chang CM, Tsai SK, Chang YL, Chou SJ, Huang SS, Tai LK, Chen YC, $\mathrm{Ku} H \mathrm{HH}, \mathrm{Li} H Y$, Chiou SH: Functional improvement of focal cerebral ischemia injury by subdural transplantation of induced pluripotent stem cells with fibrin glue. Stem Cells Dev 2010, 19:1757-1767.

21. Kawai H, Yamashita T, Ohta Y, Deguchi K, Nagotani S, Zhang X, Ikeda Y, Matsuura T, Abe K: Tridermal tumorigenesis of induced pluripotent stem cells transplanted in ischemic brain. J Cereb Blood Flow Metab 2010, 30:1487-1493.

22. Okada Y, Shimazaki T, Sobue G, Okano H: Retinoic-acid-concentrationdependent acquisition of neural cell identity during in vitro differentiation of mouse embryonic stem cells. Dev Biol 2004, 275:124-142.

23. Kim M, Habiba A, Doherty JM, Mills JC, Mercer RW, Huettner JE: Regulation of mouse embryonic stem cell neural differentiation by retinoic acid. Dev Biol 2009, 328:456-471.

24. Koch P, Opitz T, Steinbeck JA, Ladewig J, Brustle O: A rosette-type, selfrenewing human ES cell-derived neural stem cell with potential for in vitro instruction and synaptic integration. Proc Natl Acad Sci U S A 2009, 106:3225-3230.

25. Daadi MM, Maag AL, Steinberg GK: Adherent self-renewable human embryonic stem cell-derived neural stem cell line: functional engraftment in experimental stroke model. PLoS One 2008, 3:e1644.

26. Liao J, Wu Z, Wang Y, Cheng L, Cui C, Gao Y, Chen T, Rao L, Chen S, Jia N, Dai H, Xin S, Kang J, Pei G, Xiao L: Enhanced efficiency of generating induced pluripotent stem (iPS) cells from human somatic cells by a combination of six transcription factors. Cell Res 2008, 18:600-603.

27. Longa EZ, Weinstein PR, Carlson S, Cummins R: Reversible middle cerebral artery occlusion without craniectomy in rats. Stroke 1989, 20:84-91.

28. Willing AE, Lixian J, Milliken M, Poulos S, Zigova T, Song S, Hart C, SanchezRamos J, Sanberg PR: Intravenous versus intrastriatal cord blood administration in a rodent model of stroke. J Neurosci Res 2003, 73:296-307.

29. Vozeh F, Rokyta R, Ruzickova A: Stereotaxis of the rat brain in ontogenesis. Act Nerv Super 1979, 21:5-7.

30. Veizovic T, Beech JS, Stroemer RP, Watson WP, Hodges H: Resolution of stroke deficits following contralateral grafts of conditionally immortal neuroepithelial stem cells. Stroke 2001, 32:1012-1019.

31. Johansson BB: Functional outcome in rats transferred to an enriched environment 15 days after focal brain ischemia. Stroke 1996, 27:324-326.

32. Urakawa S, Hida H, Masuda T, Misumi S, Kim TS, Nishino H: Environmental enrichment brings a beneficial effect on beam walking and enhances the migration of doublecortin-positive cells following striatal lesions in rats. Neuroscience 2007, 144:920-933.

33. Fraichard A, Chassande O, Bilbaut G, Dehay C, Savatier P, Samarut J: In vitro differentiation of embryonic stem cells into glial cells and functional neurons. J Cell Sci 1995, 108:3181-3188.

34. Bain G, Kitchens D, Yao M, Huettner JE, Gottlieb DI: Embryonic stem cells express neuronal properties in vitro. Dev Biol 1995, 168:342-357.

35. Strubing C, Ahnert-Hilger G, Shan J, Wiedenmann B, Hescheler J, Wobus AM: Differentiation of pluripotent embryonic stem cells into the neuronal lineage in vitro gives rise to mature inhibitory and excitatory neurons. Mech Dev 1995, 53:275-287.

36. Zhou JM, Chu JX, Chen XJ: An improved protocol that induces human embryonic stem cells to differentiate into neural cells in vitro. Cell Biol Int 2008, 32:80-85.

37. Baharvand H, Mehrjardi NZ, Hatami M, Kiani S, Rao M, Haghighi MM: Neural differentiation from human embryonic stem cells in a defined adherent culture condition. Int J Dev Biol 2007, 51:371-378.

38. Guan K, Chang H, Rolletschek A, Wobus AM: Embryonic stem cell-derived neurogenesis: retinoic acid induction and lineage selection of neuronal cells. Cell Tissue Res 2001, 305:171-176.

39. Okabe S, Forsberg-Nilsson K, Spiro AC, Segal M, McKay RD: Development of neuronal precursor cells and functional postmitotic neurons from embryonic stem cells in vitro. Mech Dev 1996, 59:89-102.

40. Ostenfeld T, Caldwell MA, Prowse KR, Linskens MH, Jauniaux E, Svendsen $\mathrm{CN}$ : Human neural precursor cells express low levels of telomerase in vitro and show diminishing cell proliferation with extensive axonal outgrowth following transplantation. Exp Neurol 2000, 164:215-226.

41. Reynolds BA, Rietze RL: Neural stem cells and neurospheres: re-evaluating the relationship. Nat Methods 2005, 2:333-336.

42. Singec I, Knoth R, Meyer RP, Maciaczyk J, Volk B, Nikkhah G, Frotscher M, Snyder EY: Defining the actual sensitivity and specificity of the neurosphere assay in stem cell biology. Nat Methods 2006, 3:801-806. 
43. Bonnamain V, Neveu I, Naveilhan P: Neural stem/progenitor cells as a promising candidate for regenerative therapy of the central nervous system. Front Cell Neurosci 2012, 6:17.

44. Wang L, Li Y, Chen X, Chen J, Gautam SC, Xu Y, Chopp M: MCP-1, MIP-1, IL-8 and ischemic cerebral tissue enhance human bone marrow stromal cell migration in interface culture. Hematology 2002, 7:113-117.

45. Zhang H, Vutskits L, Pepper MS, Kiss JZ: VEGF is a chemoattractant for FGF-2-stimulated neural progenitors. J Cell Biol 2003, 163:1375-1384.

46. Zhao LX, Zhang J, Cao F, Meng L, Wang DM, Li YH, Nan X, Jiao WC, Zheng $M, X u X H$, Pei XT: Modification of the brain-derived neurotrophic factor gene: a portal to transform mesenchymal stem cells into advantageous engineering cells for neuroregeneration and neuroprotection. Exp Neurol 2004, 190:396-406.

47. Chen J, Zhang ZG, Li Y, Wang L, Xu YX, Gautam SC, Lu M, Zhu Z, Chopp M: Intravenous administration of human bone marrow stromal cells induces angiogenesis in the ischemic boundary zone after stroke in rats. Circ Res 2003, 92:692-699.

doi:10.1186/scrt224

Cite this article as: Yuan et al: Human induced pluripotent stem cellderived neural stem cells survive, migrate, differentiate, and improve neurologic function in a rat model of middle cerebral artery occlusion. Stem Cell Research \& Therapy 2013 4:73.

\section{Submit your next manuscript to BioMed Central and take full advantage of:}

- Convenient online submission

- Thorough peer review

- No space constraints or color figure charges

- Immediate publication on acceptance

- Inclusion in PubMed, CAS, Scopus and Google Scholar

- Research which is freely available for redistribution 